\title{
Autism spectrum disorders in adolescence and adulthood: Long-term outcomes and relevant issues for treatment and research
}

\author{
Allison B. RATTO ${ }^{*}$ \& Gary B. MESIBOV ${ }^{2}$ \\ ${ }^{1}$ Department of Psychology, University of North Carolina at Chapel Hill, Chapel Hill, NC 27599-3270, USA \\ ${ }^{2}$ Department of Psychiatry, University of North Carolina at Chapel Hill, Chapel Hill, NC 27599-3270, USA
}

\begin{abstract}
The advances in research and treatment of autism spectrum disorders (ASD) over the past three decades have focused largely on early childhood and school-age years. Although ASD is a lifelong condition, there has been relatively little attention paid to ASD during the adolescent and adulthood periods. As the population of those with ASD continues to rise and age, the need to provide research and treatment for this group has become increasingly evident. This paper reviews the current literature available on symptoms, functioning, and treatment of adolescents and adults with ASD, as well as the unique issues that arise for individuals with ASD after childhood. Adulthood outcomes for ASD are generally poor, even for those with average to above average cognitive ability. Further research and additional clinical resources are needed for this rapidly increasing group.
\end{abstract}

autism spectrum disorder (ASD), adolescence, adulthood, developmental trajectory

Citation: Ratto AB, Mesibov GB. Autism spectrum disorders in adolescence and adulthood: Long-term outcomes and relevant issues for treatment and research. Sci China Life Sci, 2015, 58: 1010-1015, doi: 10.1007/s11427-012-4295-x

The dramatic increase in the prevalence rate of autism spectrum disorders (ASD) over the past three decades has been well-documented. In the United States, the prevalence of ASD has increased nine fold over the past 30 years, rising from approximately 1 in 1000 affected individuals in the 1980s, to 1 in 110 children with a diagnosed ASD according to the most recent CDC report $[1,2]$. These rising numbers have contributed to a growing awareness of the needs of adolescents and adults with ASD. While early childhood is still seen as the most crucial period for identification and intervention, we are learning that that ASD-related challenges continue to develop and change in adolescence and adulthood. The need for research and the development of resources for this older group of individuals with ASD is becoming increasingly apparent. The aim of this review is

*Corresponding author (email: bassetta@email.unc.edu) to summarize the state of the field of ASD in adolescence and adulthood and to identify future directions for research.

\section{Developmental course}

Although most frequently diagnosed in childhood, autism spectrum disorders (ASD) are considered lifelong disabling conditions [3]. Because ASD is a developmental disorder, however, an individual's functioning and symptoms are not static across the lifespan, but rather change with the individual over the course of development [4]. Long-term outcomes vary widely across individuals, but generally speaking, outcomes for adolescents and adults with ASD tend to be somewhat poor, particularly for those with comorbid intellectual disability (ID) [5-8]. Early childhood IQ and language skills are the strongest and most consistent pre- 
dictors of adult outcomes, with higher levels of these variables leading to better long-term outcomes [5,8-10]. In particular, moderate to profound levels of ID and an absence of verbal language skills by age 5 generally predict extremely poor adult outcomes in terms of both symptoms and daily functioning [10,11]. Individuals with an average to above average IQ and more normative language abilities tend to have better long-term outcomes and to show greater levels of individual improvement in symptoms and functioning over their lifespan, though they still experience significant obstacles, and their long-term prognosis is generally poor $[4,10,12,13]$.

Despite differences in global outcomes, most individuals diagnosed with ASD as children continue to meet criteria in adolescence and adulthood [4,14,15]. Most, however, will experience some change in specific symptoms and domains of functioning over their lifetime. Verbal IQ, for instance, seems to increase over the course of development, while performance IQ and full scale IQ decrease slightly $[7,9,10]$. Overall, however, most individuals with ASD will remain in the same broad category of cognitive ability across the lifespan [13].

Among specific symptoms, communication skills are the most widely improved area of functioning [7,12,13,15], with as many as $93 \%$ of adolescents and adults showing improved language and communication skills over their lifetime [16]. The vast majority of those without comorbid ID develop verbal language as their primary form of communication, though expressive language often remains impaired and marked by speech abnormalities $[7,16]$. Around half of those with ASD with comorbid ID never develop verbal language, and those that do are markedly delayed in their language skills $[7,8,9,16]$. Impairments in nonverbal communication, such as the coordinated use of gestures and facial expression, also continue into adolescence and adulthood at all levels of cognitive ability $[4,17]$.

Most outcome studies report improvements in social skills over the course of development, though social functioning remains impaired relative to typical peers $[4,12,13,15,18]$. Again, those without comorbid ID generally show greater improvements in this area, but social functioning varies less by cognitive ability than do other symptoms [4,16]. The most commonly reported areas of social improvement are in social responsiveness and conversational skills, whereas the quality of friendships and other relationships remains impaired [4,7]. There are some reports of adults with ASD getting married or developing long-term intimate relationships, but these relationships are still extremely rare [5-7].

In contrast to the lifetime improvement observed in communication and social functioning, the severity of restricted/repetitive behaviors and interests appears to be relatively stable over time, though many note that the form and complexity of these behaviors often does change substantially $[10,12,16,18]$. In addition to the core symptoms of
ASD, most individuals on the spectrum experience difficulties in related areas, such as executive function and theory of mind. While no long-term outcome studies have examined change across time in these domains as of yet, deficits in these areas have been found in separate studies in childhood, adolescence, and adulthood [19-22], indicating that these are likely persistent deficits. Additionally, short-term longitudinal studies and cross-sectional studies have found age-related improvements in both theory of mind and executive function in ASD during childhood, but not in adolescence, indicating that the development of these skills likely levels off during adolescence [20,23,24]. As with other symptom domains, higher cognitive ability is also associated with better theory of mind and executive function skills $[20,24]$. Furthermore, many adolescents and adults without comorbid ID actually perform similarly to typically developing individuals on basic tasks of emotion recognition and theory of mind, but continue to struggle with more complex emotions and higher-order theory of mind scenarios [19,25].

As of yet, there is little research published on the manifestation of ASD in the elderly. The only published paper to date presented a case series of five individuals diagnosed with Asperger syndrome from an outpatient psychiatric center for the elderly in the United Kingdom [26]. The authors presented their approach to diagnosis, emphasizing the importance of obtaining a full developmental history, appropriate cognitive assessments, and relevant self-report and observer-report questionnaires. The authors also underlined the importance of diagnosing and treating ASD in later-life stages, as it may impact functioning and treatment decisions. As the rising population of children and adolescents with ASD continues to age, those that work in geriatric psychiatry will be faced with the challenge of addressing the needs of the elderly with ASD and the compounding difficulties of senility and dementia. Research is clearly needed to highlight and address these issues.

\section{Related outcomes and concerns}

Low academic achievement and unemployment/underemployment are quite high in this population, with many individuals achieving at significantly lower levels than their IQ scores alone would predict [9,10,27]. Adolescents with comorbid ID are likely to remain in the school system until age 21 , usually with substantial academic accommodations [28]. The final years of schooling for this group should focus on transition planning, and specifically on preparing the individual for future vocational settings. Unfortunately, transitional programs are often poorly run and school systems frequently have little to no communication with future vocational placement programs, resulting in difficulties for the individual and his/her family in preparing for life after the school years [29]. Adults with ASD and comorbid ID often end up unemployed or working in menial jobs in 
sheltered workshops or supported employment programs that do not provide a living wage [7,9]. Some programs have found success using more individually tailored vocational placements and supports, and have found that positive vocational outcomes often lead to more positive outcomes in cognitive and psychosocial functioning as well [30-33].

Adults without comorbid ID tend to have higher academic achievement than those with comorbid ID, and some are now obtaining advanced degrees ranging from the associate to the doctoral level $[27,34]$. This in turn leads to more successful vocational outcomes, in jobs ranging from sales and administrative assistants to more advanced positions such as software engineers or even college professors [7,27]. Most adults with ASD do not achieve to their full academic potential, however, and the majority are underemployed [27]. Additionally, most report considerably more negative than positive employment experiences, usually related to the social aspects of the workplace, rather than to specific job skills [27].

In addition to generally poor vocational outcomes, few adults with ASD live independently-only 4\%-12\% [7-9]. Most adults with ASD and comorbid ID require fairly consistent support in daily living skills, and thus are often in full-time residential care or living with family members $[7,8]$. Even those individuals without ID often end up living with family or in supported living as well, due to impairments in daily living skills and social skills, as well as to related issues of underemployment [9,35]. Regardless of residential status, experiences of social isolation, loneliness and a generally poor self-reported quality of life are widespread in this population [36-38].

Genetic factors and comorbidities are most often discussed in the context of risk for ASD, but genetics may also play an important role in adolescence and adulthood. As many as $10 \%$ of individuals with ASD have a comorbid genetic disorder [39]. Among these, the most commonly reported are Angelman syndrome, Fragile X syndrome, and Rett syndrome, which is considered a pervasive developmental disorder separate from autism within the DSM-IV-TR [39]. These disorders and other comorbid genetic syndromes often include medical pathologies and risks, as well as unique behavioral and developmental impairments. As with symptoms of ASD, these challenges continue to develop and manifest themselves in adolescence and adulthood. These individuals may have to learn to manage medical treatments or receive supervised medical care. Additionally, the unique neurological and behavioral aspects of these genetic disorders may further complicate the development of educational, vocational, and self-care skills. Many of these syndromes also have negative impacts on fertility, which should be discussed in adolescence and adulthood.

Psychiatric and medical comorbidities are quite high in this population, occurring in up to $64 \%$ of adolescents and adults with ASD [10]. Epilepsy is the most commonly re- ported medical comorbidity, occurring in up to $38 \%$ of individuals on the spectrum [40,41]. A slightly elevated mortality rate has also been reported; while it is unclear what accounts for this finding, it is thought to be attributable to more frequent accidents such as ingesting poisons and traffic accidents $[8,14]$. The most commonly reported psychiatric disorders are affective disorders, particularly social anxiety and depression, which together occur in as a many as half of adults with ASD [5,8,9,42,43]. Increased rates of obsessive-compulsive disorder, Tourette's syndrome, and attention-deficit/hyperactivity disorder have also been found in individuals on the spectrum $[5,8,9]$.

While psychiatric and medical comorbidities are an issue for most individuals with ASD, as these individuals move from childhood into adolescence and adulthood, issues around sexuality become relevant for all. Sexuality has been identified as an important issue by individuals with ASD and their families, but unfortunately it has received little attention in the research literature and is often avoided in by clinicians [44]. The limited studies available on this topic have found that the majority of individuals with ASD, with and without comorbid ID, express interest in dating and physical intimacy and are engaged in sexual behavior (most commonly masturbation), but often lack basic factual knowledge about anatomy and sexuality [44-46]. Sexual education for individuals with ASD should address the topics of privacy, personal hygiene, appropriate forms of physical contact with others, anatomy, and comprehensive sexual education, tailored to the needs, interests, and cognitive ability of each individual $[47,48]$. While there is scant research available on the efficacy of intervention strategies, behavioral management programs have been shown to successfully treat inappropriate sexual behaviors for adolescents and adults with ID (e.g., public masturbation, inappropriate touching) $[48,49]$.

Interactions with the legal system are also an issue during adolescence and adulthood, though again, they have been infrequently attended to in the literature. Individuals with developmental disabilities such as ASD are significantly more likely to be victims of crime and abuse than typically developing individuals, and also have greater difficulty reporting their victimization [50]. There is also increasing evidence that individuals with ASD, particularly high-functioning autism/Asperger syndrome, are overrepresented in the criminal justice system [51]. The data seem to suggest that the vast majority of offenders with ASD have comorbid psychiatric and/or substance use disorders, particularly among those who are violent offenders [52,53]. Nonetheless, it is important for professionals and families to keep in mind that the difficulties in communication, empathy, and social understanding, as well as the tendency toward preoccupations and ritualized behavior may put individuals with ASD at a greater risk of perpetrating crimes, often without full comprehension of the nature and implications of the act [54]. 


\section{Treatment and intervention}

With the change in symptoms and most relevant issues in adolescence and adulthood, the focus of treatment changes as well. Most of the research-based interventions for this population have focused on improving the social skills of high-functioning adolescents and adults [55]. These interventions are most often conducted as groups, based on the idea that this offers individuals the chance to practice social skills with one another and learn through modeling, though as of yet there is no evidence to support the efficacy of group over individual interventions [56]. Social skills treatments for ASD may target a range of social skills, from basic goals such as improving conversational skills, emotion knowledge, and problem-solving, to more advanced skills such as perspective taking, social awareness, and empathy-building [55-60]. As of now, these studies frequently report improvements on discrete measures of social functioning, such as emotion recognition and social knowledge and high participant satisfaction, but unfortunately participants continue to struggle to generalize these improvements to daily social environments $[56,57,60]$.

In hopes to build the generalizability of social skills interventions, some researchers have begun developing computer and virtual-reality based social skills interventions for adolescents and adults with ASD. Although controlled testing has yet to be conducted, pilot testing indicates that these interventions are feasible and well-received by participants [61-63]. Recently, there has also been an increased interest in the treatment of anxiety and depression in this population as well, due to its connection to social impairments among high-functioning individuals on the spectrum [64-67]. At least one intervention has been developed to jointly target social anxiety and concurrent social skills for adolescents with ASD, using modified cognitive-behavioral strategies and psychoeducation, and has been found to be feasible and well-tolerated [68]. Interventions for lower-functioning adolescents and adults with ASD are rarely mentioned in the literature, and tend to focus on behavioral management of inappropriate or self-injurious behaviors.

\section{Summary}

Since its initial identification by Kanner in 1943, our understanding of autism spectrum disorders has advanced considerably. Unfortunately, our understanding of how these disorders change and manifest themselves in adolescence and adulthood has continued to lag considerably behind our understanding of their appearance in early childhood. However, the rising prevalence of ASD and aging of this population means that we can no longer afford to ignore the unique challenges of ASD in adolescence and adulthood. Further research is needed in several areas. First and foremost, we need a better understanding of how adults with
ASD are impacted by their disorder and what factors mediate and moderate these outcomes. It is now clear that early cognitive and language abilities, which are often impacted by early intervention, strongly predict adult outcomes. More information is still needed, however, about the influence of internal and external factors in adolescence and adulthood on long-term outcomes and functioning. Moreover, there is a great need for research identifying which outcomes have the most meaning for individuals on the spectrum and their families. These stakeholders must be consulted in the development of future interventions and supports, as they have too often been neglected in the development of research targets. Further research is also needed to better understand the transition from childhood to adulthood. Although clinicians have identified social communication skills, daily living skills, sexuality, and vocational skills, as important areas for consideration during this time, evidence-based interventions have yet to be developed to successfully target each of these critical domains. In particular, continuing research is needed to evaluate and improve the outcomes of social skills groups and other symptom-focused interventions for adolescents and adults with ASD, particularly those with comorbid ID. As the proportion of high-functioning individuals on the spectrum has grown, research on lower-functioning adolescents and adults has become largely neglected, despite their continuing needs and ability to learn. Finally, research on quality of life as perceived by individuals and their families must be expanded and applied to future research. By understanding how those directly impacted by ASD define "good" and "poor" outcomes, we can better target our interventions and research to address the areas of greatest importance to these individuals.

1 Newschaffer CJ, Croen LA, Daniels J, Giarelli E, Grether JK, Levy SE, Mandell DS, Miller LA, Pinto-Martin J, Reaven J, Reynolds AM, Rice CE, Schendel D, Windham GC. The epidemiology of autism spectrum disorders. Ann Rev Public Health, 2007, 28: 235-258

2 Rice C. Prevalence of autism spectrum disorders: Autism and developmental disabilities monitoring network, United States, 2006. Surveil Sum, 2009, 58: 1-20

3 American Psychiatric Association. Diagnostic and Statistical Manual of Mental Disorders-text Revision. (4th ed, text revision). Washington, DC: American Psychiatric Association, 2000

4 McGovern CW, Sigman M. Continuity and change from early childhood to adolescence in autism. J Child Psychol Psychiat, 2005, 46: 401-408

5 Eaves LC, Ho HH. Young adult outcome of autism spectrum disorders. J Aut Dev Disord, 2008, 38: 739-747

6 Engstrom I, Ekstrom L, Emilsson B. Psychosocial functioning in a group of Swedish adults with Asperger syndrome or high-functioning autism. Autism, 2003, 7: 99-110

7 Howlin P, Goode S, Hutton J, Rutter M. Adult outcome for children with autism. J Child Psychol Psychiat, 2004, 45: 212-229

8 Kobayashi R, Murata T, Yoshinaga K. A follow-up study of 201 children with autism in Kyushu and Yamaguchi areas, Japan. J Aut Dev Disord, 1992, 22: 395-411

9 Farley MA, McMahon WM, Fombonne E, Jenson WR, Miller J, Gardner M, Block H, Pingree CB, Ritvo ER, Ritvo RA, Coon H. Twenty-year outcome for individuals with autism and average or 
near-average cognitive abilities. Aut Res, 2009, 2: 109-118

10 Seltzer MM, Shattuck P, Abbeduto L, Greenberg JS. Trajectory of development in adolescents and adults with autism. Ment Retard Dev Disabil Res Rev, 2004, 10: 234-247

11 Nordin V, Gillberg C. The long-term course of autistic disorders: Update on follow-up studies. Acta Psych Scand, 1998, 97: 99-108

12 Piven J, Harper J, Palmer P, Arndt S. Course of behavioral change in autism: A retrospective study of high-IQ adolescents and adults. J Am Acad Child Adoles Psychiat, 1996, 35: 523-529

13 Shattuck PT, Seltzer MM, Greenberg JS, Orsmond GI, Bolt D, Kring $\mathrm{S}$, Lounds J, Lord C. Change in autism symptoms and maladaptive behaviors in adolescents and adults with an autism spectrum disorder. J Aut Dev Disord, 2007, 37: 1735-1747

14 Billstedt E, Gillberg IC, Gillberg C. Autism after adolescence: Population based 13- to 22-year follow-up study of 120 individuals with autism diagnosed in childhood. J Aut Dev Disord, 2005, 35: 351-360

15 Seltzer MM, Krauss MW, Shattuck PT, Orsmond G, Swe A, Lord C. The symptoms of autism spectrum disorders in adolescence and adulthood. J Aut Dev Disord, 33, 2003: 565-581

16 Ballaban-Gil K, Rapin I, Tuchman R, Shinnar S. Longitudinal examination of the behavioral, language, and social changes in a population of adolescents and young adults with autistic disorder. Pediatr Neurol, 1996, 15: 217-223

17 Cederlund M, Hagberg B, Billstedt E, Gillberg IC, Gillberg C. Asperger syndrome and autism: A comparative longitudinal follow-up study more than 5 years after original diagnosis. J Aut Dev Disord, 2008, 38: 72-85

18 Billstedt E, Gillberg IC, Gillberg C. Autism in adults: symptoms patterns and early childhood predictors. Use of the DISCO in a community sample followed from childhood. J Child Psychol Psychiat, 2007, 48: 1102-1110

19 Golan O, Baron-Cohen S, Hill J. The Cambridge Mindreading (CAM) face voice battery: Testing complex emotion recognition in adults with and without Asperger syndrome. J Aut Dev Disord, 2006, 36: 169-183

20 Happé F, Booth R, Charlton R, Hughes C. Executive function deficits in autism spectrum disorder and attention-deficit/hyperactivity disorder: Examining profiles across domains and ages. Brain Cogn, 2006, 61: 25-39

21 Landa RJ, Goldberg MC. Language, social, and executive functions in high-functioning autism: A continuum of performance. J Aut Dev Disord, 2005, 35: 557-573

22 Luna B, Doll SK, Hegedus SJ, Minshew NJ, Sweeney JA. Maturation of executive function in autism. Biol Psychiat, 2006, 61: 474-481

23 Ozonoff S, McEvoy R. A longitudinal study of executive function and theory of mind development in autism. Dev Psychopathol, 1994, 6: 415-431

24 Sparrevohn R, Howie PM. Theory of mind in children with autistic disorder: Evidence of developmental progression and the role of verbal ability. J Child Psychol Psychiat, 1995, 36: 249-263

25 Baron-Cohen S, Jolliffe T, Mortimore C, Robertson M. Another advanced test of theory of mind: Evidence from very high functioning adults with autism or Asperger syndrome. J Child Psychol Psychiat, 1997, 38: 813-822

26 James IA, Mukaetova-Ladinska E, Reichelt FK, Briel R, Scully A. Diagnosing Aspergers syndrome in the elderly: A series of case presentations. Int J Geriatr Psychiatry, 2006, 21: 951-960

27 Muller E, Schuler A, Burton BA, Yates G. Meeting the vocational support needs of individuals with Asperger syndrome and other autism spectrum disabilities. J Voc Rehab, 2003, 18: 163-175

28 Moxon L, Gates D. Children with autism: Supporting the transition to adulthood. Educ Child Psychol, 2001, 18: 28-40

29 Nuehring ML, Sitlington PL. Transition as a vehicle: Moving from high school to an adult vocational service provider. J Disabil Policy Studies, 2003, 14: 23-35

30 Garcia-Villamisar D, Hughes C. Supported employment improves cognitive performance in adults with autism. J Intell Disabil Res, 2007, 51: 142-150

31 Keel JH, Mesibov GB, Woods AV. TEACCH-supported employment program. J Aut Dev Disord, 1997, 27: 3-9

32 Mawhood L, Howlin P. The outcome of a supported employment scheme for high-functioning adults with autism or Asperger syndrome. Autism, 1999, 3: 229-254

33 Smith MD, Coleman D. Managing the behavior of adults with autism in the job setting. J Aut Dev Disord, 1986, 16: 145-154

34 Schaller J, Yang NK. Competitive employment for people with autism: Correlates of successful closure in competitive and supported employment. Rehab Couns Bull, 2005, 49: 4-16

35 Hurlbutt K, Chalmers L. Adults with autism speak out: Perceptions of their life experiences. FOCUS, 2002, 17: 103-111

36 Jennes-Coussens M, Magill-Evans J, Koning C. The quality of life of young men with Asperger syndrome. Autism, 2006, 10: 403-414

37 Lasgaard M, Nielsen A, Eriksen ME, Goossens L. Loneliness and social support in adolescent boys with autism spectrum disorders. J Aut Dev Disord, 2010, 40: 218-226

38 Muller E, Schuler A, Yates GB. Social challenges and supports from the perspective of individuals with Asperger syndrome and other autism spectrum disabilities. Autism, 2008, 12: 173-190

39 Abrahams BS, Geschwind DH. Advances in autism genetics: On the threshold of a new neurobiology. Nat Rev Genetics, 2008, 9: 341-355

40 Danielsson S, Gillberg IC, Billstedt E, Gillberg C, Olsson I. Epilepsy in young adults with autism: A prospective population-based follow-up study of 120 individuals diagnosed in childhood. Epilepsia, 2005, 46: 918-923

41 Rossi PG, Posar A, Parmeggiani A. Epilepsy in adolescents and young adults with autistic disorder. Brain Dev, 2000, 22: 102-106

42 Ghaziuddin M, Ghaziuddin N, Greden J. Depression in persons with autism: Implications for research and clinical care. J Aut Dev Disord, 2002, 32: 299-306

43 Tantam D. Psychological disorder in adolescents and adults with Asperger syndrome. Autism, 2000, 4: 47-62

44 Stokes MA, Kaur A. High-functioning autism and sexuality: A parental perspective. Autism, 2005, 9: 266-289

45 Ousley OY, Mesibov GB. Sexual attitudes and knowledge of high-functioning adolescents and adults with autism. J Aut Dev Disord, 1991, 21: 471-481

46 Van Bourgondien M, Reichle NC, Palmer A. Sexual behavior in adults with autism. J Aut Dev Disord, 1997, 27: 113-125

47 Koller R. Sexuality and adolescents with autism. Sexual Disabil, 2000, 18: 125-135

48 Mesibov GB. Sex education for people with autism: Matching programs to levels of functioning. Paper presented at the meeting of the National Society for Children and Adults with Autism, Omaha, NE, 1982

49 Servais L. Sexual health care in persons with intellectual disabilities. Ment Retard Dev Disabil Res Rev, 2006, 12: 48-56

50 Petersilia JR. Crime victims with developmental disabilities: A review essay. Crim Just Beh, 2001, 28: 655-694

51 Cashin A, Newman C. Autism in the criminal justice detention system: A review of the literature. J Forensic Nurs, 2009, 5: 70-75

52 Langstrom N, Grann M, Ruchkin V, Sjöstedt G, Fazel S. Risk factors for violent offending in autism spectrum disorder: A national study of hospitalized individuals. J Interpers Violence, 2009, 24: 1358-1370

53 Newman SS, Ghaziuddin M. Violent crime in Asperger syndrome: The role of psychiatric comorbidity. J Aut Dev Disord, 2008, 38: 1848-1852

54 Mayes TA. Persons with autism and criminal justice: Core concepts and leading cases. J Pos Beh Interventions, 2003, 5: 92-100

55 Solomon M, Goodlin-Jones BL, Anders TF. A social adjustment enhancement intervention for high functioning autism, Asperger's syndrome, and pervasive developmental disorder NOS. J Aut Dev Disord, 2004, 34: 649-668

56 Duncan AW, Klinger LG. Autism spectrum disorders: Building social skills in group, school, and community settings. Social Work Groups, 2010, 33: 175-193

57 Reichow B, Volkmar FR. Social skills interventions for individuals 
with autism: Evaluation for evidence-based practices within a best evidence synthesis framework. J Aut Dev Disord, 2010, 40: 149-166

58 Tse J, Strulovtich J, Tagalakis V, Meng L, Fombonne E. Social skills training for adolescents with Asperger syndrome and high-functioning autism. J Aut Dev Disord, 2007, 37: 1960-1968

59 Turner-Brown LM, Perry TD, Dichter GS, Bodfish JW, Penn DL. Brief report: Feasibility of social cognition and interaction training for adults with high functioning autism. J Aut Dev Disord, 2008, 38 : 1777-1784

60 Williams S, Keonig K, Scahill L. Social skills development in children with autism spectrum disorders: A review of the intervention research. J Aut Dev Disord, 2007, 37: 1858-1868

61 Cobb S, Beardon L, Eastgate R, Glover T, Kerr S, Neale H. Applied virtual environments to support learning of social interaction skills in users with Asperger's syndrome. Digital Creativity, 2002, 13: 11-22

62 Parsons S, Leonard A, Mitchell P. Virtual environments for social skills training: Comments from two adolescents with autistic spectrum disorder. Comput Educ, 2006, 47: 186-206

63 Rajendran G, Mitchell P. Computer mediated interaction in Asper- ger's syndrome: The Bubble Dialogue program. Comput Educ, 2000, 35: 189-207

64 Bellini S. The development of social anxiety in adolescents with autism spectrum disorders. Autism, 2006, 21: 138-145

65 Farrugia S, Hudson J. Anxiety in adolescents with Asperger syndrome: Negative thoughts, behavioral problems, and life interference. FOCUS, 2006, 21: 25-35

66 Kuusikko S, Pollock-Wurman R, Jussila K, Carter AS, Mattila ML, Ebeling H, Pauls DL, Moilanen I. Social anxiety in high-functioning children and adolescents with autism and Asperger syndrome. J Aut Dev Disord, 2008, 38: 1697-1709

67 White SW, Roberson-Nay R. Anxiety, social deficits, and loneliness in youth with autism spectrum disorders. J Aut Dev Disord, 2009, 39: 1006-1013

68 White SW, Albano AM, Johnson CR, Kasari C, Ollendick T, Klin A, Oswald D, Scahill L. Development of a cognitive-behavioral intervention program to treat anxiety and social deficits in teens with high-functioning autism. Clin Child Family Psych Rev, 2010, 13: 77-90

Open Access This article is distributed under the terms of the Creative Commons Attribution License which permits any use, distribution, and reproduction in any medium, provided the original author(s) and source are credited. 